CAHIER DE RECHERCHE \#1705E

WORKING PAPER \#1705E

Département de science économique

Department of Economics

Faculté des sciences sociales

Université d'Ottawa

Faculty of Social Sciences

University of Ottawa

\title{
Two-sided Learning and Short-Run Dynamics in a New Keynesian Model of the Economy*
}

\author{
Christian Matthes ${ }^{\dagger}$ and Francesca Rondina ${ }^{\ddagger}$
}

March 2017

\footnotetext{
${ }^{*}$ The views expressed in this article are those of the authors and do not necessarily reflect the position of the Federal Reserve Bank of Richmond or the Federal Reserve System.

${ }^{\dagger}$ Federal Reserve Bank of Richmond, email: christian.matthes@ rich.frb.org.

$¥$ Corresponding author. Department of Economics, University of Ottawa, 120 University Private, Ottawa, Ontario, Canada, K1N 6N5; e-mail; frondina@uottawa.ca.
} 


\begin{abstract}
We investigate the role of asymmetric information and learning in a New Keynesian framework in which private agents and the central bank have imperfect knowledge of the economy. We assume that agents employ the data that they observe to form beliefs about the relationships that they do not know, use their beliefs to decide on actions, and revise these beliefs through a statistical learning algorithm as new information becomes available. Using simulations, we show that asymmetric information and learning can significantly change the dynamics of the variables of the model.
\end{abstract}

Key words: Asymmetric Information, Learning, Expectations, Monetary Policy.

JEL Classification: E37, E47, E52. 


\section{Introduction}

This note studies asymmetric information and two-sided learning in a New Keynesian framework in which private agents do not know the monetary policy rule and do not observe monetary policy shocks, while the central bank has imperfect knowledge about the behavior of private agents. We assume that agents use all the information that they have available to estimate the structural equations of the model that they do not know, and use a statistical learning algorithm to update their beliefs as new data become available. In each period, these beliefs will be the basis for policy decisions (on the side of the central bank) and for production and pricing decisions (on the side of private agents).

The literature on monetary policy in environments characterized by imperfect knowledge and learning is extensive. ${ }^{1}$ Two-sided learning was first studied in the seminal work of Marcet and Sargent (1989), upon which most of the ensuing research (including this paper) is built. We employ a framework that departs from the previous literature in this area in two directions. First, we assume that agents are only forming beliefs on the equilibrium relationships that they do not know rather than estimating reduced-form regressions on all equilibrium variables (as, for instance, in Dennis and Ravenna, 2008). Second, we assume that both sides of the economy are implementing optimal choices. As a consequence, our analysis does not focus on the ability of the central bank to enforce a particular policy rule or to achieve convergence to a rational expectations equilibrium (as, for instance, in Evans and Honkapohja, 2003). Instead, the goal of this note is to study the short-run dynamics that the interactions of beliefs and actions can generate.

To what extent can asymmetric information and learning affect the time-series properties of the variables of interest? We address this question by examining the results of simulations performed using a New Keynesian model with parameters calibrated to standard values. Our results indicate that asymmetric information and two-sided learning can significantly alter the dynamics of the model compared to the situation in which the economy is operating at a rational expectations equilibrium (REE).

\section{The Model}

The true model of the economy is a standard New Keynesian framework; the specification is similar to Dennis and Ravenna (2008). The private sector is described by the equations:

$$
y_{t}=E_{t}^{P A}\left(y_{t+1}\right)-\frac{1}{\sigma}\left(i_{t}-E_{t}^{P A}\left(\pi_{t+1}\right)-r_{t}^{n}\right)
$$

\footnotetext{
${ }^{1}$ For a review, see Evans and Honkapohja (2009).
} 


$$
\begin{gathered}
\pi_{t}=\frac{1}{(1+\beta)} \pi_{t-1}+\frac{\beta}{(1+\beta)} E_{t}^{P A}\left(\pi_{t+1}\right)-\frac{\kappa}{(1+\beta)} y_{t}+w_{t} \\
r_{t}^{n}=\bar{r}+u_{t} \\
u_{t}=\rho_{u} u_{t-1}+\varepsilon_{t}^{u} \\
w_{t}=\rho_{w} w_{t-1}+\varepsilon_{t}^{w}
\end{gathered}
$$

where $y_{t}$ is the output gap, $\pi_{t}$ the inflation rate, $i_{t}$ the nominal interest rate, $r_{t}^{n}$ the natural rate of interest (which is the sum of its steady state value $\bar{r}$ and a shock $u_{t}$ ), and $w_{t}$ can be interpreted as a shock to the marginal cost of production. Both $u_{t}$ and $w_{t}$ evolve according to an $A R(1)$ process, as described by (4) and (5), with $\varepsilon_{t}^{u} \sim$ i.i.d.(0, $\left.\sigma_{u}^{2}\right)$ and $\varepsilon_{t}^{w} \sim$ i.i.d. $\left(0, \sigma_{w}^{2}\right)$. The operator $E_{t}^{P^{A}}(\cdot)$ in (1) and (2) denotes the fact that private agents form expectations based on their own information set.

The economy is also populated by a central bank, which controls $i_{t}$ through the policy instrument $x_{t}$ according to:

$$
i_{t}=x_{t}+v_{t}
$$

where $v_{t}$ is a monetary policy shocks, which follows the $A R(1)$ process:

$$
v_{t}=\rho_{v} v_{t-1}+\varepsilon_{t}^{v}
$$

Agents do not have full knowledge of the economy: the central bank does not observe the shocks $u_{t}$ and $w_{t}$, and does not know how private agents form expectations and decide about prices and output, while private agents do not know the policy rule that the central bank uses to set $x_{t}$ and do not observe the monetary policy shock $v_{t}$. We assume that each agent uses the available data to estimate the relationships that they do not know, and employs the perceived model of the economy to make their respective decisions. These steps are updated in each period as new information is observed over time.

All agents use the same vector $z_{t}^{R}$ to estimate the unknown structural relationships of the model: ${ }^{2}$

$$
z_{t}^{R}=\left[\begin{array}{llll}
y_{t} & \pi_{t} & i_{t} & 1
\end{array}\right]^{\prime}
$$

Private agents estimate the unknown monetary policy rule as:

$$
i_{t}=z_{t-1}^{R \prime} \psi_{t}+\omega_{t}^{P A}
$$

\footnotetext{
${ }^{2}$ The results do not change if we allow private agents to use $u_{t}$ and $w_{t}$, and the central bank to use $v_{t}$, when estimating the unknown relationships of the model. The learning algorithm typically ends up attaching a coefficients of zero to the variables that are only observed by one side and not the other.
} 
Similarly, the monetary authorities estimate the unknown private side of the economy as:

$$
\begin{aligned}
& y_{t}=z_{t-1}^{R \prime} c_{y t}+\omega_{y t}^{C B} \\
& \pi_{t}=z_{t-1}^{R \prime} c_{\pi t}+\omega_{\pi t}^{C B}
\end{aligned}
$$

We assume that agents use a standard recursive least squares algorithm (see Evans and Honkapohja, 2001) to update $\psi_{t}, c_{y t}$ and $c_{\pi t}$. The linear relationships in (9), (10) and (11), can be written in a general form as:

$$
q_{t}=z_{t-1}^{R \prime} \phi_{t}+\eta_{t}
$$

where $q_{t}$ is either $i_{t}, y_{t}$, or $\pi_{t}, \phi_{t}$ is the vector of parameters, and $\eta_{t}$ the residual. Using this notation, the learning algorithm is written as:

$$
\begin{gathered}
R_{t}=R_{t-1}+g_{t}\left(z_{t-1}^{R} z_{t-1}^{R \prime}-R_{t-1}\right) \\
\phi_{t}=\phi_{t-1}+g_{t} R_{t}^{-1} z_{t-1}^{R}\left(q_{t}-z_{t-1}^{R \prime} \phi_{t-1}\right)
\end{gathered}
$$

Our simulations focus on Recursive Least Squares (RLS) learning, in which $g_{t}=\frac{1}{t_{0}+t}$.

In our framework, the error $\omega_{t}^{P A}$ affects private agents' expectations and perceived law of motion (PLM), and we assume that private agents estimate its variance as: ${ }^{3}$

$$
\widehat{\sigma}_{\omega t}^{2}=\widehat{\sigma}_{\omega t-1}^{2}+g_{t}\left[\left(i_{t}-\psi_{t} z_{t-1}^{R}\right)^{2}-\widehat{\sigma}_{\omega t-1}^{2}\right]
$$

We augment our learning algorithm with a projection facility. More specifically, we allow private agents to disregard estimates of (9) for which the solution of the expectational difference equation implied by (1) and (2) does not exist, and policymakers to rule out estimates of (10) and (11) for which the central bank's perceived law of motion for $y_{t}, i_{t}$, and $\pi_{t}$ is not stable. ${ }^{4}$ In practice, this projection facility is never invoked in our simulations.

Policymakers and private agents base their decisions on their respective PLMs. All agents are assumed to behave as anticipated utility decision makers (Kreps, 1998), so they treat parameter estimates as true values, and disregard parameter uncertainty and the effects of learning.

The PLM for private agents is obtained from (1) - (5) and (9). We assume the same timing as Cogley et al. (2011): private agents first estimate the parameters of (9) using

\footnotetext{
${ }^{3}$ An online Appendix explains why the estimated variance of the policy shocks enters the PLM (and thus the actual law of motion, ALM) in our case.

${ }^{4}$ If the projection facility is active, we assume that agents will use their estimates from the previous periods as beliefs.
} 
data up to time $t-1$, then observe current period shocks (except for the monetary policy shock) and the value of the policy instrument, and finally use all this information to solve the expectational difference equation implied by the equilibrium conditions and the estimated policy rule. We use Sims'(2001) Gensys program to find this solution, and we do not rule out the possibility of indeterminate equilibria.

The central bank, on the other hand, decides the value of the policy instrument $x_{t}$ by minimizing the quadratic loss function:

$$
E_{t-1}^{C B} \sum_{j=0}^{\infty} \beta^{j}\left[\left(\pi_{t+j}\right)^{2}+\lambda_{y}\left(y_{t+j}\right)^{2}+\lambda_{i}\left(i_{t+j}-i_{t+j-1}\right)^{2}\right]
$$

given (10) and (11), and the estimated values of $c_{y t}$ and $c_{\pi t}$. The operator $E_{t-1}^{C B}$ indicates that expectations are formed with respect to the information available to the central bank. The optimization problem is repeated in every period given updated values of $c_{y t}$ and $c_{\pi t}$; thus, the optimal interest rate rule will be changing over time:

$$
i_{t}=f_{0 t}+f_{\pi t} \pi_{t-1}+f_{y t} y_{t-1}+f_{i t} i_{t-1}+v_{t}
$$

The ALM for the model is obtained from (1) - (7), private agents' decisions for $E_{t}^{P A}\left(y_{t+1}\right)$ and $E_{t}^{P A}\left(\pi_{t+1}\right)$, and policymakers' interest rate rule in (15). In matrix form, this ALM can be written as:

$$
z_{t}=\Psi_{1, t} z_{t-1}+\Psi_{2, t} \varepsilon_{t}
$$

where

$$
\begin{gathered}
z_{t}=\left[\begin{array}{lllllllll}
y_{t} & \pi_{t} & i_{t} & u_{t} & w_{t} & v_{t} & E_{t}^{P A}\left(y_{t+1}\right) & E_{t}^{P A}\left(\pi_{t+1}\right) & 1
\end{array}\right]^{\prime} \\
\varepsilon_{t}=\left[\begin{array}{lll}
\varepsilon_{t}^{u} & \varepsilon_{t}^{w} & \varepsilon_{t}^{v}
\end{array}\right]^{\prime}
\end{gathered}
$$

The matrices $\Psi_{1, t}$ and $\Psi_{2, t}$ and further details about the PLMs and ALM for the model are given in an Appendix available online. ${ }^{5}$

\section{Simulation Exercises}

The optimization approach of policymakers and the expectation formation process of private agents are highly nonlinear functions of the estimated parameters, and the equilibrium of our model cannot be characterized analytically. Thus, we study its dynamics using Monte Carlo simulations. We set: $\sigma=1 ; \kappa=0.4 ; \beta^{P A}=\beta^{C B}=0.99 ; \bar{r}=1 / \beta^{P A}-1 ; \lambda_{y}=1$

\footnotetext{
${ }^{5}$ https://sites.google.com/site/francescarondina/AppendixTSL.pdf
} 
and $\lambda_{i}=0.5$. For the shocks, we assume normal distributions with parameters: $\sigma_{\varepsilon^{u}}^{2}=0.5^{2}$; $\sigma_{\varepsilon^{w}}^{2}=0.5^{2} ; \sigma_{\varepsilon^{v}}^{2}=0.5^{2} ; \rho_{u}=0 ; \rho_{w}=0 ; \rho_{v}=0 .{ }^{6}$ The data is measured quarterly, and the variables are interpreted as annualized rates. In the RLS algorithm we set $t_{0}=20$ (5 years). ${ }^{7}$ In all the exercises, we set the period length to $T=200$ (50 years), and we perform $N=500$ simulations.

We compute the ordinary differential equation of Marcet and Sargent (1989) numerically and we find that, given the chosen parameter values, our model converges to a symmetric and learnable, but indeterminate, self-confirming equilibrium (SCE). ${ }^{8}$ As point of departure and comparison for the dynamics of our model, we use the rational expectation equilibrium (REE) that emerges when policymakers maintain a fixed policy rule for $x_{t}$, while private agents continue to learn and compute expectations using the procedure described in the previous section. The specific policy rule that we employ is:

$$
x_{t}=0.1 i_{t-1}+(1-0.1)\left[0.5 y_{t-1}+1.5 \pi_{t-1}+\bar{r}\right]
$$

While this rule is chosen arbitrarily, its sole purpose is to provide a REE that we can employ as starting point for the analysis.

Table 1 reports our results. Column (1) describes the behavior of the variables at the REE. In the other scenarios, we let policymakers and private agents implement the full learning and decision procedure, but we consider different sets of initial beliefs on the parameters $c_{y t}, c_{\pi t}$, and $\psi_{t}$ (specified at the top of each column in Table 1). ${ }^{9}$ In columns (1)-(2), agents' initial beliefs are consistent with the long-run equilibrium of the economy. On the other hand, columns (3)-(5) study scenarios in which the beliefs of one or both sides of the economy are on the process of moving from the their initial REE values towards their SCE values.

Three main results emerge from Table 1. Column (2) shows that two-sided learning can alter the behavior of the variables relative to the REE case, even when beliefs are already at their SCE values. Columns (3)-(5) suggest that when the beliefs of at least one side of the economy are changing, the learning and decision sequence implied by our model can affect the correlations between variables in terms of magnitude and/or sign. Finally, column (5) indicates that policymakers' changing beliefs might be particularly important for the dynamics of the economy, as they seem to have an impact on the volatility of the variables

\footnotetext{
${ }^{6}$ The simplyfing assumption of uncorrelated exogenous shocks is made to fully focus on the persistence arising from the dynamics of our model.

${ }^{7}$ We also experimented with $t_{0}=40$ and $g_{t}=g=0.01$ (constant gains), and we found that the results were very similar.

${ }^{8}$ For all values of the parameters within a reasonable range, the SCE is indeterminate.

${ }^{9}$ The value of $\widehat{\sigma}_{\omega, 0}^{2}$ is the same (0.5) in both the REE and the SCE.
} 
and their persistence, in addition to their correlations.

\begin{tabular}{|c|c|c|c|c|c|}
\hline & $\underset{(1)}{\mathrm{REE}}$ & $\begin{array}{c}c_{y 0}, c_{\pi 0} \text { at } \mathrm{SCE} \\
\psi_{0} \text { at } \mathrm{SCE} \\
(2)\end{array}$ & $\begin{array}{c}c_{y 0}, c_{\pi 0} \text { at REE } \\
\psi_{0} \text { at } \mathrm{REE} \\
(3)\end{array}$ & $\begin{array}{c}c_{y 0}, c_{\pi 0} \text { at SCE } \\
\psi_{0} \text { at REE } \\
(4)\end{array}$ & $\begin{array}{c}c_{y 0}, c_{\pi 0} \text { at REE } \\
\psi_{0} \text { at SCE } \\
(5)\end{array}$ \\
\hline$\sigma_{y}$ & 0.869 & 0.756 & 0.780 & 0.768 & 0.806 \\
\hline$\sigma_{\pi}$ & 0.575 & 0.740 & 0.684 & 0.592 & 1.033 \\
\hline$\sigma_{i}$ & 0.811 & 0.614 & 0.745 & 0.616 & 0.816 \\
\hline autocorr $_{y}$ & 0.201 & 0.580 & 0.449 & 0.478 & 0.692 \\
\hline autocorr $_{\pi}$ & 0.368 & 0.527 & 0.597 & 0.435 & 0.735 \\
\hline autocorr $_{i}$ & -0.130 & 0.252 & 0.724 & 0.340 & 0.747 \\
\hline$\sigma_{y, \pi}$ & -0.538 & -0.228 & -0.133 & -0.537 & 0.086 \\
\hline$\sigma_{y, i}$ & -0.811 & -0.424 & -0.739 & -0.724 & 0.132 \\
\hline$\sigma_{\pi, i}$ & 0.165 & 0.266 & -0.406 & 0.065 & 0.650 \\
\hline
\end{tabular}

Table 1 - Summary statistics for $y_{t}, \pi_{t}$, and $i_{t}$ under different scenarios.

Figure 1 provides some insights about the speed of convergence of agents' beliefs and actions. This figure shows the difference between the actual policy parameters $F_{t}$ and private agents' beliefs $\psi_{t}$ in all the simulated patterns for the scenario reported in column (3) of Table 1. As evident from the top panels of the figure, for some of the parameters convergence can be extremely slow.
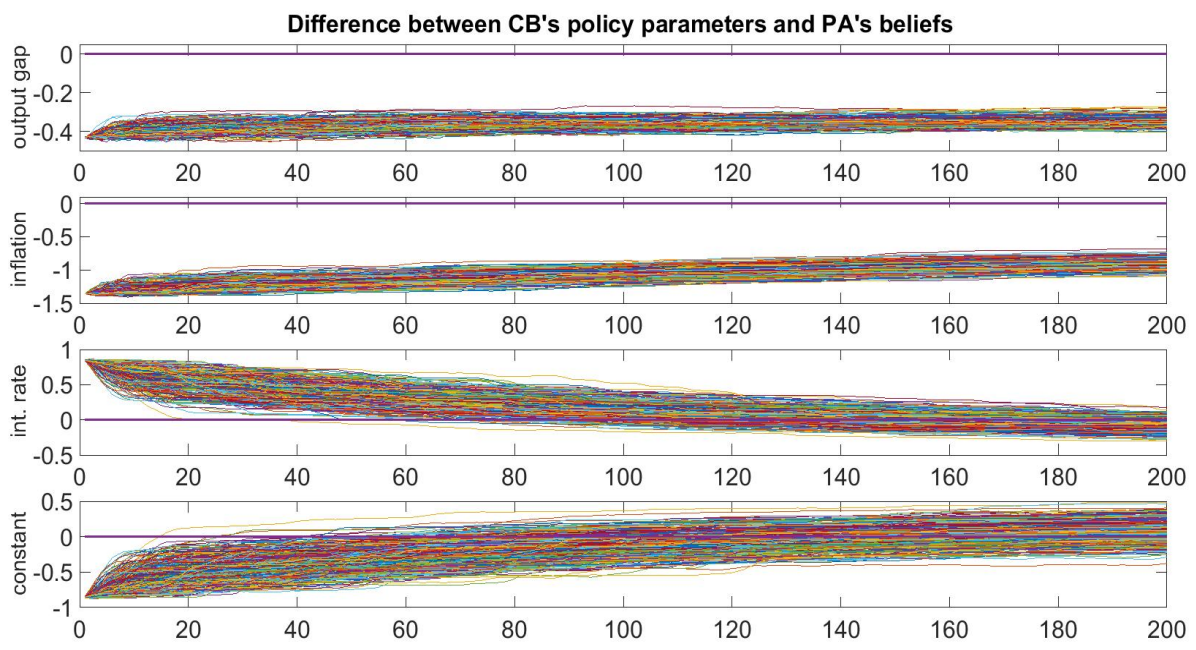

Figure 1 - Converge between private agents' beliefs and actual policy parameters. 


\section{Conclusions}

This note represents a first attempt to investigate the role of asymmetric information and two-sided learning in a New Keynesian framework in which both private agents and policymakers are behaving optimally given their knowledge of the economy. The results of our simulations show that two-sided learning can have important consequences on the relationships between variables, particularly when the beliefs of the central bank are still adjusting towards their (long-run) SCE values.

\section{Acknowledgments}

This note is a revised version of a manuscript that previously circulated with the title "Two-

sided Learning in New Keynesian Models: Dynamics, (Lack of) Convergence and the Value of Information ". 


\section{References}

[1] Cogley, T., Matthes, C., Sbordone, A. M., 2011. Optimal Disinflation Under Learning. FRB of New York Staff Report No. 524.

[2] Dennis, R., Ravenna, F., 2008. Learning and optimal monetary policy. Journal of Economic Dynamics and Control, 32(6), 1964-1994.

[3] Evans, G.W., Honkapohja, S., 2001. Learning and Expectations in Macroeconomics. Princeton University Press, Princeton.

[4] Evans, G.W., Honkapohja, S., 2003. Adaptive Learning and Monetary Policy Design. Journal of Money, Credit and Banking, 35, 1045-1072.

[5] Evans, G.W., Honkapohja, S., 2009. Expectations, Learning and Monetary Policy: An Overview of Recent Research. In: Klaus Schmidt-Hebbel and Carl E. Walsh (eds.), Monetary Policy under Uncertainty and Learning, Central Bank of Chile, pp. 27-76.

[6] Kreps, D., 1998. Anticipated Utility and Dynamic Choice, in D.P. Jacobs, E. Kalai, and M. Kamien, eds., Frontiers of Research in Economic Theory, (Cambridge: Cambridge University Press), 242-74.

[7] Marcet, A., Sargent, T., 1989. Convergence of least squares mechanisms in self-referential linear stochastic models. Journal of Economic Theory 48, 337- 368.

[8] Sims, C.A., 2001. Solving Linear Rational Expectations Models. Computational Economics 20,1-20. 


\title{
Appendix to Two-sided Learning and Short-Run Dynamics in a New Keynesian Model*
}

\author{
Christian Matthes ${ }^{\dagger}$ Francesca Rondina ${ }^{\ddagger}$
}

\section{Matrices in the PLMs for private agents and the central bank}

The true model of the economy is a standard New Keynesian framework, as developed by Gali (2008); the specification that we use is similar to Dennis and Ravenna (2008). We assume perfect indexation of prices that cannot be reset to past inflation, as in Christiano et al. (2001). ${ }^{1}$

Private agents' behavior in this economy can be described by the following equations:

$$
\begin{gathered}
y_{t}=E_{t}^{P A}\left(y_{t+1}\right)-\frac{1}{\sigma}\left(i_{t}-E_{t}^{P A}\left(\pi_{t+1}\right)-r_{t}^{n}\right) \\
\pi_{t}=\frac{1}{(1+\beta)} \pi_{t-1}+\frac{\beta}{(1+\beta)} E_{t}^{P A}\left(\pi_{t+1}\right)-\frac{\kappa}{(1+\beta)} y_{t}+w_{t} \\
r_{t}^{n}=\bar{r}+u_{t} \\
u_{t}=\rho_{u} u_{t-1}+\varepsilon_{t}^{u} \\
w_{t}=\rho_{w} w_{t-1}+\varepsilon_{t}^{w}
\end{gathered}
$$

where all the variables are as described in the paper. In addition the central bank controls the nominal interest rate $i_{t}$ through the policy instrument $x_{t}$ according to the equation:

$$
i_{t}=x_{t}+v_{t}
$$

where $v_{t}$ is a monetary policy shocks, which is assumed to follow the $\mathrm{AR}(1)$ process:

$$
v_{t}=\rho_{v} v_{t-1}+\varepsilon_{t}^{v}
$$

*The views expressed in this appendix are those of the authors and don't necessarily reflect the position of the Federal Reserve Bank of Richmond or the Federal Reserve System.

${ }_{\dagger}^{\dagger}$ Federal Reserve Bank of Richmond, email: christian.matthes@rich.frb.org

${ }^{\ddagger}$ University of Ottawa, email: frondina@uottawa.ca

${ }^{1}$ This assumption ensures that the pricing equations are unaffected by the presence of positive trend inflation, so that the steady state output level is independent of the steady state inflation level. See Ascari (2004) for a discussion. 
Private agents estimate:

$$
i_{t}=z_{t-1}^{R \prime} \psi_{t}+\omega_{t}^{P A}
$$

while the central bank estimates:

$$
\begin{aligned}
& y_{t}=z_{t-1}^{R \prime} c_{y t}+\omega_{y t}^{C B} \\
& \pi_{t}=z_{t-1}^{R \prime} c_{\pi t}+\omega_{\pi t}^{C B}
\end{aligned}
$$

where in both cases:

$$
z_{t}^{R}=\left[\begin{array}{llll}
y_{t} & \pi_{t} & i_{t} & 1
\end{array}\right]^{\prime}
$$

The central bank, chooses the policy rule for $x_{t}$ by minimizing the expected discounted quadratic loss function:

$$
E_{t-1}^{C B} \sum_{j=0}^{\infty} \beta^{j}\left[\left(\pi_{t+j}\right)^{2}+\lambda_{y}\left(y_{t+j}\right)^{2}+\lambda_{i}\left(i_{t+j}-i_{t+j-1}\right)^{2}\right]
$$

given (9) and (10), and the estimated values of $c_{y t}$ and $c_{\pi t}$. Since the central bank's optimization problem is repeated in every period given updated values of $c_{y t}$ and $c_{\pi t}$, the optimal policy vector will be dependent on the current period estimates of these parameters and it will be changing over time: $x_{t}=-F_{t} z_{t-1}^{R}$. The expression for the nominal interest rate becomes:

$$
i_{t}=f_{0 t}+f_{\pi t} \pi_{t-1}+f_{y t} y_{t-1}+f_{i t} i_{t-1}+v_{t}
$$

The matrices of the PLM for the central bank can easily be obtained using (9), (10), and the policy rule (13).

$$
\begin{aligned}
\left(\begin{array}{ccccc}
1 & 0 & 0 & 0 & 0 \\
0 & 1 & 0 & 0 & 0 \\
0 & 0 & 1 & -1 & 0 \\
0 & 0 & 0 & 1 & 0 \\
0 & 0 & 0 & 0 & 1
\end{array}\right)\left(\begin{array}{c}
y_{t} \\
\pi_{t} \\
i_{t} \\
v_{t} \\
1
\end{array}\right) & =\left(\begin{array}{ccccc}
c_{1 y t} & c_{2 y t} & c_{3 y t} & 0 & c_{4 y t} \\
c_{1 \pi t} & c_{2 \pi t} & c_{3 \pi t} & 0 & c_{4 \pi t} \\
-f_{\pi t} & -f_{y t} & -f_{i t} & 0 & -f_{0 t} \\
0 & 0 & 0 & \rho_{v} & 0 \\
0 & 0 & 0 & 0 & 1
\end{array}\right)\left(\begin{array}{c}
y_{t-1} \\
\pi_{t-1} \\
i_{t-1} \\
v_{t-1} \\
1
\end{array}\right)+ \\
& +\left(\begin{array}{ccc}
1 & 0 & 0 \\
0 & 1 & 0 \\
0 & 0 & 0 \\
0 & 0 & 1 \\
0 & 0 & 0
\end{array}\right)\left(\begin{array}{c}
\omega_{y t}^{C B} \\
\omega_{\pi t}^{C B} \\
\varepsilon_{t}^{v}
\end{array}\right)
\end{aligned}
$$


or:

$$
A^{C B} z_{t}^{C B}=\left(C_{t}^{C B}-B^{C B} F_{t}\right) z_{t-1}^{C B}+D^{C B} \varepsilon_{t}^{C B}
$$

This expression gives the PLM for the Central Bank:

$$
z_{t}^{C B}=\Phi_{1, t} z_{t-1}^{C B}+\Phi_{2} \varepsilon_{t}^{C B}
$$

where $\Phi_{1, t}=\left(A^{C B}\right)^{-1}\left(C_{t}^{C B}-B^{C B} F_{t} Q^{C B}\right)$ and $\Phi_{2}=\left(A^{C B}\right)^{-1} D^{C B}$.

The PLM for private agents is given by the equations of the model (1) - (4) together with the perceived interest rate rule (8). These equations can be rewritten in matrix form as:

$$
\left.\begin{array}{ccccccccccc}
1 & 0 & \frac{1}{\sigma} & -\frac{1}{\sigma} & 0 & 0 & 0 & -\frac{1}{\sigma} \\
\frac{\kappa}{(1+\beta)} & 1 & 0 & 0 & -1 & 0 & 0 & 0 \\
0 & 0 & 1 & 0 & 0 & 0 & 0 & 0 \\
0 & 0 & 0 & 1 & 0 & 0 & 0 & 0 \\
0 & 0 & 0 & 0 & 1 & 0 & 0 & 0 \\
& 0 & 0 & 0 & 0 & 0 & 1 & 0 & 0 \\
& 0 & 0 & 0 & 0 & 0 & 0 & 1 & 0 \\
& 0 & 0 & 0 & 0 & 0 & 0 & 0 & 1
\end{array}\right)\left(\begin{array}{c}
y_{t} \\
\pi_{t} \\
i_{t} \\
u_{t} \\
w_{t} \\
E_{t}^{P A}\left(y_{t+1}\right) \\
E_{t}^{P A}\left(\pi_{t+1}\right) \\
1
\end{array}\right)=
$$


or

$$
A^{P A} z_{t}^{P A}=B^{P A} E_{t}^{P A}\left(z_{t+1}^{P A}\right)+C_{t}^{P A} z_{t-1}^{P A}+D^{P A} \varepsilon_{t}^{P A}
$$

The solution will take the form:

$$
z_{t}^{P A}=\Gamma_{1, t} z_{t-1}^{P A}+\Gamma_{2, t} \varepsilon_{t}^{P A}
$$

thus

$$
E_{t}^{P A}\left(z_{t+1}^{P A}\right)=\Gamma_{1, t} z_{t}^{P A}
$$

and we can rewrite

$$
A^{P A} z_{t}^{P A}=B^{P A} \Gamma_{1, t} z_{t}^{P A}+C_{t} z_{t-1}^{P A}+D^{P A} \varepsilon_{t}^{P A}
$$

This expression can be used to solve for $\Gamma_{1, t}$ and $\Gamma_{2, t}$; we use Sims'(2001) Gensys program for this purpose and we allow for the possibility of an indeterminate solution. 


\section{Matrices in the ALM}

The ALM for the variables in the model can be obtained from the true equations $(1)-(4)$ together with the true interest rate rule expressed by (13), and can be written in matrix form as:

$$
\begin{aligned}
& \left(\begin{array}{ccccccccc}
1 & 0 & \frac{1}{\sigma} & -\frac{1}{\sigma} & 0 & 0 & 0 & 0 & -\frac{1}{\sigma} \bar{r} \\
\frac{\kappa}{(1+\beta)} & 1 & 0 & 0 & -1 & 0 & 0 & 0 & 0 \\
0 & 0 & 1 & 0 & 0 & 0 & 0 & 0 & 0 \\
0 & 0 & 0 & 1 & 0 & 0 & 0 & 0 & 0 \\
0 & 0 & 0 & 0 & 1 & 0 & 0 & 0 & 0 \\
0 & 0 & 0 & 0 & 0 & 1 & 0 & 0 & 0 \\
0 & 0 & 0 & 0 & 0 & 0 & 1 & 0 & 0 \\
0 & 0 & 0 & 0 & 0 & 0 & 0 & 1 & 0 \\
0 & 0 & 0 & 0 & 0 & 0 & 0 & 0 & 1
\end{array}\right)\left(\begin{array}{c}
y_{t} \\
\pi_{t} \\
i_{t} \\
u_{t} \\
w_{t} \\
v_{t} \\
E_{t}^{P A}\left(y_{t+1}\right) \\
E_{t}^{P A}\left(\pi_{t+1}\right) \\
1
\end{array}\right)= \\
& \left(\begin{array}{ccccccccc}
1 & \frac{1}{\sigma} & 0 & 0 & 0 & 0 & 0 & 0 & 0 \\
0 & \frac{\beta}{(1+\beta)} & 0 & 0 & 0 & 0 & 0 & 0 & 0 \\
0 & 0 & 0 & 0 & 0 & 0 & 0 & 0 & 0 \\
0 & 0 & 0 & 0 & 0 & 0 & 0 & 0 & 0 \\
0 & 0 & 0 & 0 & 0 & 0 & 0 & 0 & 0 \\
0 & 0 & 0 & 0 & 0 & 0 & 0 & 0 & 0 \\
1 & 0 & 0 & 0 & 0 & 0 & 0 & 0 & 0 \\
0 & 1 & 0 & 0 & 0 & 0 & 0 & 0 & 0 \\
0 & 0 & 0 & 0 & 0 & 0 & 0 & 0 & 0
\end{array}\right) E_{t}^{P A}\left[\left(\begin{array}{c}
y_{t+1} \\
\pi_{t+1} \\
i_{t+1} \\
u_{t+1} \\
w_{t+1} \\
v_{t+1} \\
E_{t+1}^{P A}\left(y_{t+2}\right) \\
E_{t+1}^{P A}\left(\pi_{t+2}\right) \\
1
\end{array}\right)\right]+ \\
& +\left(\begin{array}{ccccccccc}
0 & 0 & 0 & 0 & 0 & 0 & 0 & 0 & 0 \\
0 & \frac{1}{(1+\beta)} & 0 & 0 & 0 & 0 & 0 & 0 & 0 \\
\psi_{y t} & \psi_{\pi t} & \psi_{i t} & 0 & 0 & 0 & 0 & 0 & \psi_{0 t} \\
0 & 0 & 0 & \rho_{u} & 0 & 0 & 0 & 0 & 0 \\
0 & 0 & 0 & 0 & \rho_{w} & 0 & 0 & 0 & 0 \\
0 & 0 & 0 & 0 & 0 & \rho_{v} & 0 & 0 & 0 \\
0 & 0 & 0 & 0 & 0 & 0 & 0 & 0 & 0 \\
0 & 0 & 0 & 0 & 0 & 0 & 0 & 0 & 0 \\
0 & 0 & 0 & 0 & 0 & 0 & 0 & 0 & 1
\end{array}\right)\left(\begin{array}{c}
y_{t-1} \\
\pi_{t-1} \\
i_{t-1} \\
u_{t-1} \\
w_{t-1} \\
v_{t-1} \\
E_{t-1}^{P A}\left(y_{t}\right) \\
E_{t-1}^{P A}\left(\pi_{t}\right) \\
1
\end{array}\right)+\left(\begin{array}{ccc}
0 & 0 & 0 \\
0 & 0 & 0 \\
0 & 0 & 1 \\
1 & 0 & 0 \\
0 & 1 & 0 \\
0 & 0 & 0 \\
0 & 0 & 0 \\
0 & 0 & 0 \\
0 & 0 & 0
\end{array}\right)\left(\begin{array}{c}
\varepsilon_{t}^{u} \\
\varepsilon_{t}^{w} \\
\varepsilon_{t}^{v}
\end{array}\right)
\end{aligned}
$$

or:

$$
A z_{t}=B E_{t}^{P A}\left(z_{t+1}^{P A}\right)+C_{t} z_{t-1}+D \varepsilon_{t}
$$


Due to indeterminacy, the matrices of the ALM have an invertibility issue. To side-step this problem, we plug in the PLM of private agents twice to get:

$$
\begin{aligned}
E_{t}^{P A}\left(z_{t+1}^{P A}\right) & =\Gamma_{1, t} z_{t}^{P A} \\
& =\Gamma_{1, t}^{2} z_{t-1}^{P A}+\Gamma_{1, t} \Gamma_{2, t} \varepsilon_{t}^{P A}
\end{aligned}
$$

and from this we can write:

$$
A z_{t}=B\left(\Gamma_{1, t}^{2} M^{P A} z_{t-1}+\Gamma_{1, t} \Gamma_{2, t} \varepsilon_{t}^{P A}\right)+C_{t} z_{t-1}+D \varepsilon_{t}
$$

where $M^{P A}$ is a matrix selecting the elements of $z_{t}^{P A}$ from $z_{t}$. Notice that the elements of $\varepsilon_{t}^{P A}$ can be written as a function of the elements of $\varepsilon_{t}$ and $z_{t-1}$, since $\varepsilon_{t}^{u}$ and $\varepsilon_{t}^{w}$ are included in $\varepsilon_{t}$ and

$$
\begin{aligned}
\omega_{t}^{P A} & =i_{t}-\psi_{t} z_{t-1}^{R} \\
& =-\left(F_{t}+\psi_{t}\right) z_{t-1}^{R}+v_{t} \\
& =-\left(F_{t}+\psi_{t}\right) z_{t-1}^{R}+\varepsilon_{t}^{v}
\end{aligned}
$$

where the last step follows from the simplifying assumption that we made in the implementation of our model that $\rho_{v}=0$. Notice however that $\omega_{t}^{P A}$ enters in (15). For this reason, we adjust the model to account for private agents' perceived variance of $\omega_{t}^{P A}$ as follows:

$$
\begin{aligned}
\varepsilon_{t}^{P A} & =\left(\begin{array}{ccc}
1 & 0 & 0 \\
0 & 1 & 0 \\
0 & 0 & \sigma_{v} / \widehat{\sigma}_{\omega t}
\end{array}\right) \varepsilon_{t} \\
& -\left(\begin{array}{cccc}
0 & 0 & 0 & 0 \\
0 & 0 & 0 & 0 \\
0 & 0 & 1 / \widehat{\sigma}_{\omega t} & 0
\end{array}\right)\left(F_{t}+\psi_{t}\right) z_{t-1}^{R}
\end{aligned}
$$

or:

$$
\begin{array}{r}
\varepsilon_{t}^{P A}=S_{1} \varepsilon_{t}+S_{2} z_{t-1}^{R} \\
S_{1} \varepsilon_{t}+S_{2} M^{R} z_{t-1}
\end{array}
$$

where $\widehat{\sigma}_{\omega t}$ is the estimated standard deviation of $\omega_{t}^{P A}$, and $M^{R}$ is a matrix selecting the elements of $z_{t-1}^{R}$ from $z_{t-1}$. Finally, the ALM of the model can be written as:

$$
z_{t}=\Psi_{1, t} z_{t-1}+\Psi_{2, t} \varepsilon_{t}
$$


where

$$
\begin{gathered}
\Psi_{1, t}=A^{-1}\left(B \Gamma_{1, t}^{2} M^{P A}+C+\Gamma_{1, t} \Gamma_{2, t} S_{2} M^{R}\right) \\
\Psi_{2, t}=A^{-1}\left(D+\Gamma_{1, t} \Gamma_{2, t} S_{1}\right)
\end{gathered}
$$

\section{References}

[1] Ascari, G. , 2004. Staggered prices and trend inflation: some nuisances. Review of Economic Dynamics, 7(3), 642-667.

[2] Christiano, L.J., Eichenbaum, M., Evans, C.L., 2005. Nominal rigidities and the dynamic effects of a shock to monetary policy. Journal of Political Economy, University of Chicago Press, 113(1), 1-45.

[3] Dennis, R., Ravenna, F., 2008. Learning and optimal monetary policy. Journal of Economic Dynamics and Control, 32(6), 1964-1994.

[4] Galí, J., 2008. Monetary Policy, Inflation, and the Business Cycle: An Introduction to the New Keynesian Framework. Princeton University Press.

[5] Sims, C.A., 2001. Solving Linear Rational Expectations Models. Computational Economics 20, 1-20. 